\title{
Risk diversification by European financial conglomerates*
}

\author{
Jan Frederik Slijkerman ${ }^{\dagger} \quad$ Dirk Schoenmaker ${ }^{\ddagger}$ \\ Casper G. de Vries $^{\S}$
}

February 26, 2006

\begin{abstract}
We study the dependence between the downside risk of European banks and insurers. Since the downside risk of banks and insurers differs, an interesting question from a supervisory point of view is the risk reduction that derives from diversification within large banks and financial conglomerates. We discuss the limited value of the normal distribution based correlation concept, and propose an alternative measure which better captures the downside dependence given the fat tail property of the risk distribution. This measure is estimated and indicates better diversification benefits for conglomerates versus large banks.
\end{abstract}

\section{Introduction}

Since the lifting of the regulatory barriers for mergers between banks and insurers in the US, there has been an ongoing discussion on the appropriate regulatory framework for financial conglomerates. If the risk profile of insurance activities of a newly formed conglomerate is different from the risk profile of banking activities, this gives scope for diversification. Regulators

${ }^{\dagger}$ Erasmus University Rotterdam, Tinbergen Institute

${ }^{\ddagger}$ Vrije Universiteit Amsterdam, Ministry of Finance (NL)

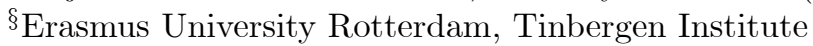


might then allow lower capital requirements for a conglomerate than for its individual constituent parts. If lower capital requirements are allowed, this reduces the cost of capital and hence increases profitability.

As an input for this discussion we investigate the dependence between the downside risk of European banks and insurers. If the downside dependence between a bank and an insurer is distinctly different from the dependence structure between two banks or between two insurers, financial conglomerates might require less capital charges than large banks or insurance companies. Since we analyze risk from the perspective of a supervisor, we focus primarily on a measure of downside risk and do not use global risk measures like the variance. In the banking sector this focus on downside risk is evidenced by the emphasis on the Value at Risk (VaR) methodology. This perspective complements other research which takes the perspective from shareholders, investigating possible economies of scale and scope (e.g. Carow, 2001).

It is a stylized fact that the return series of financial assets are fat tailed distributed (Jansen and De Vries, 1991). The commonly maintained assumption that returns are normally distributed therefore underestimates the downside risk. Hence, given the focus on downside risk, we will not start from this premise and allow for fat tails to capture the univariate risk properties. For the multivariate question of downside risk diversification benefits, the normal distribution based correlation concept is also of limited value. For example, one can have multivariate Student-t distributed random variables, which exhibit fat tails, are dependent, but which are nevertheless uncorrelated. Research based on the correlation concept, to investigate the diversification benefits of banks into insurance activities, appears therefore inappropriate. To answer the question whether the capital requirements for conglomerates can be lower than the sum of requirements for large banks, we employ a downside risk measure which directly evaluates the systemic downside risk in terms of failure probabilities and losses. This measure is derived from Extreme Value Theory (EVT), and easily allows for the non-normality.

Financial conglomerates may exploit diversification possibilities between balance sheet items of banks and insurers. However, current regulation does not allow for cross hedging. The different entities of a conglomerate are supervised separately according to sector specific regulation. Since there is no common regulatory framework, capital has a distinct function in both banking and insurance. EU solvency requirements for insurers do e.g. not depend on credit risk. This makes it difficult to examine cross-sector risk transfers and may induce regulatory arbitrage. The current supervisory framework in 
banking is based on the Basle 1988 Capital Accord for the credit book and on the "Amendment to the capital accord to incorporate market risks" of 1996. The insurance regulation is based on the insurance directives in the EU and on the Risk Based Capital framework in the US. For the supervision of financial groups the financial conglomerates directive is in place. New regulation based on internal risk models for the banking sector is being implemented (Basle II Capital Accord). For the insurance sector the European Commission is working on a new regulatory framework, the so-called Solvency 2 project. The tendency is to tie regulatory capital more closely to Economic Capital models (e.g. Bikker and Lelyveld, 2002). These models enable financial institutions to allocate capital optimally, based on an economic concept of risk. If financial conglomerates face a lower risk, this validates lower capital requirements, which would boost return on investments.

The objective of supervision is to protect depositors and policyholders and more broadly to foster financial stability. To this end regulators promote the soundness of individual institutions and the stability of the financial system. Regulators are especially interested in the frequency and magnitude of extreme shocks to the system, which threaten the continuity of banks and insurers. Statistically speaking regulators are interested in the lower quantiles of the distribution of returns.

Most of the research on the stability of the financial system has a primary focus on the stability of the banking sector, due to the importance of the payment and clearing functions for the real economy. This activity comes as a joint product from the other banking activities and is a positive externality to the economy. A similar service does not derive from the insurance activities. Moreover, the type of contracts like a deposit makes that the banking sector is more fragile than the insurance sector. A survey of the issue of systemic risk can be found in De Bandt and Hartmann (2002). The Basel Committee on Banking Supervision (1999) provides a good overview of the empirical impact of banking regulation, specifically the 1988 Accord. The systemic aspects and the potential threat to the financial stability of insurers has not gained that much interest. One of the first studies raising this question was written by the Group of Thirty (1997). More recently Swiss Re (2003) concluded that there is ample systemic risk in the reinsurance sector. Even though the stability of the insurance sector is perhaps of a lesser public concern than the fragility of the banking sector, the presence of financial conglomerates, nevertheless requires an assessment of the downside risk derived from both activities.

In the empirical section we begin by measuring the riskiness of individual 
banks and insurers. We use the reduced form approach of the risk of financial institutions as analyzed by De Vries (2005) and employed in De Nicolo and Kwast (2002) and Hartmann, Straetmans and De Vries (2004). This involves estimating the probability of a crash by using daily stock price data. We employ estimators from statistical extreme value theory and avoid correlation based techniques which focus primarily on the central order statistics. The estimation results for individual firms provide information on the risk of individual institutions and allows for a cross-sector comparison of individual firm risk. Our main research question concerns whether the downside risk in the banking sector differs from the downside risk in the insurance sector. To this end we estimate the dependence between combinations of firms, both within a sector and across sectors. If the risk profile of both sectors is different, this creates risk diversification possibilities for financial conglomerates. To understand the possible differences in cross-sector risk, we develop an analytical model which helps us to interpret the tail dependence. This model provides an explanation for the differences in dependence between banks and insurers, compared to the dependence within the same sector.

The early work on the benefits of mergers between banks and insurers was done in light of the discussion on the abolishment of the Glass-Steagall act in the US (which forbid bank holding companies to perform insurance activities). For a literature overview see Laderman (1999) or Estrella (2001). Estrella (2001) applies option pricing theory to create a measure of failure for a firm and finds that banks and insurers are likely to experience diversification gains. The literature review of Berger (2000) suggests that most efficiency gains of mergers appear to be linked to benefits from risk diversification. A study by Oliver, Wyman \& Company (2001) argues that there is scope for a reduction of 5-10\% in capital requirements for a combined bank and insurance company. Carow (2001) analyses the Citicorp-Travelers Group merger by an event study approach and finds that investors expect significant benefits from the removal of regulatory barriers to bancassurance. However, in the meantime this merger is in the process of breaking up. Laderman (1999) finds that substantial investments in life insurance underwriting are optimal for reducing the risk of the return on assets for bank holding companies. Except for Gully et al. (2001) and Bikker and Lelyveld (2002), most studies focus on U.S. data, as in De Nicolo and Kwast (2002), and assume that the returns are normally distributed. Our research is focused on European data and applies extreme value theory, allowing for fat tails.

In the remainder of this paper we first describe the limited value of the 
correlation concept and provide another dependence measure. Next we provide an economic rationale for dependence, between different financial institutions. Thereafter, we explain the empirical methodology, give a description of the data and present the results. Finally, we summarize our findings and draw some policy conclusions.
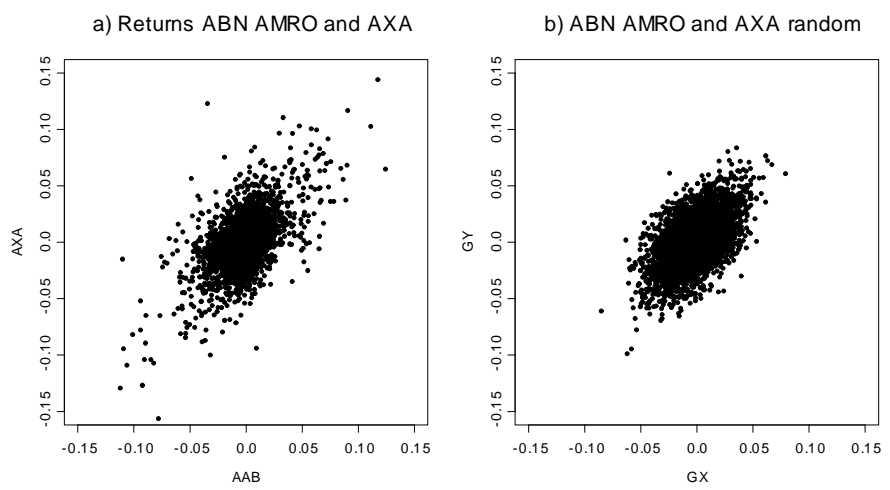

Figure 1: Normal distribution underestimates risk

\section{Dependence and correlation}

To understand the dependence between two random variables which follow a normal distribution it is sufficient to know the mean, variance and correlation coefficient to characterize their joint behavior. The correlation measure itself, however, is often not an useful statistic for financial data for various reasons. First, economists are interested in the risk-return trade-off, to which the correlation measure is only an intermediate step. Boyer, Gibson and Loretan (1997), moreover, noticed that even if the normal model applies, verifying the market speak of increased correlation coefficients in times of crisis can be illusory. Forbes and Rigobon (2002) show that not much of a correlation change can be identified around crisis times, by taking into account the simultaneous increase in variance of the return series.

A second reason for the failure of the normal based correlation measure is that the return series are clearly non-normal distributed. In Figure 1a we have depicted the daily stock returns of ABN AMRO Bank and AXA since 1992. We estimated the mean, variance and correlation of these returns and 
randomly generated returns with the same parameters assuming a bivariate normal distribution (Figure 1b). Project the observations along the two axes to obtain the univariate properties of the return series. The difference between the returns and the artificial returns is that in the latter sample there are no observations larger than 10 percent. The normal model, in fact, predicts that returns above the 10 per cent occur with a very low probability, while such returns are in reality quite common. Thus the return distributions exhibit fat tails. Since regulators are concerned with the extreme losses of value for banks and insurers, the assumption of normality therefore appears inappropriate.
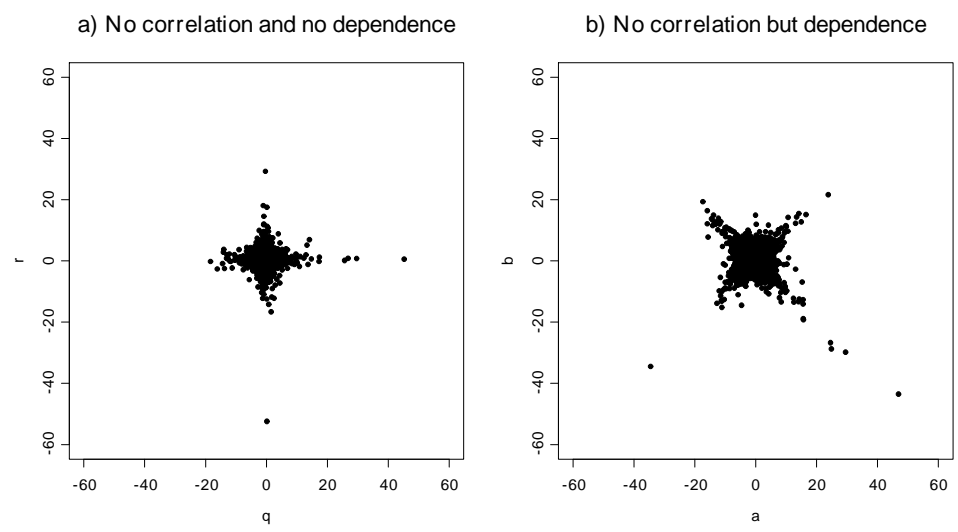

Figure 2: Two student-t distributed variables

The third reason as to why the multivariate normal based correlation measure is inappropriate for our analysis, is that it does not capture very well the dependency which one observes in the above plots. The true data have most of the extreme outcomes realized close to the diagonal, and thus occur jointly. In the normal remake, this is much less the case. To explain how this could be, we provide an example which is somewhat of an exaggeration, but which provides the key insight very well. The example builds on the fact that if two random variables are dependent, the correlation between the variables may nevertheless be zero. In Figure 2a, two uncorrelated and independent random variables, $q_{i}$ and $r_{i}$ are shown (based on 10,000 randomly generated Student-t variables with 3 degrees of freedom). In contrast to Figure $2 \mathrm{a}$, where two independent variables are plotted, the variables $a_{i}$ and $b_{i}$ 
in Figure 2b are made dependent. We formed two portfolio's, $a_{i}=q_{i}+r_{i}$ and $b_{i}=q_{i}-r_{i}$. On the x-axis on finds the sum $\left(a_{i}=q_{i}+r_{i}\right)$ of the two Student-t variables, on the y-axis one finds the difference $\left(b_{i}=q_{i}-r_{i}\right)$ between the two random variables; one can think of the second portfolio being short in the asset with return $r_{i}$. The correlation between $a$ and $b$ is zero, but note that there is dependence between the portfolios in Figure $2 \mathrm{~b}$ as all extremes occur jointly along the two diagonals. In contrast, if $q_{i}$ and $r_{i}$ are drawn from a normal distribution, $a_{i}$ and $b_{i}$ are surely independent as they are uncorrelated. In that case a cross plot of $a_{i}$ and $b_{i}$ would generate a neat circle around zero. This illustrates that the characteristics of variables which are in the domain of the fat tailed Frechet extreme value distribution differ considerably from e.g. variables which follow a normal distribution. The sample maxima of these distributions all converge to the Frechet limit, when appropriately scaled. A typical feature of the Student-t distribution, which is in the domain of the Frechet, are the extremely high and low observations far away from the centre. In a sample of heavy tailed random variables, the maximum observation dominates all others (in such a way that the sum and the maximum over a large threshold have approximately the same probability $^{1}$ ). This shows in Figure 2a as the larger observations appear along the two axes. In this figure the extreme observations are located alongside the axes since the probability of a pair of two large variables is so low. Therefore combinations $a_{i}=q_{i}+r_{i}$ and $b_{i}=q_{i}-r_{i}$ in Figure $2 \mathrm{~b}$ far from the origin are almost entirely driven by either the $q_{i}$ or the $r_{i}$, placing the largest observations on the two diagonals (which are essentially a rotation of the two axes from Figure 2a). In other words, the largest observation really dominates over the others and determines the scale and the dependence. Because of the shortcomings of the correlation measure, we want to use a measure that provides us with the probability of multiple extreme losses, taking into account that return series of stock prices are fat tailed.

${ }^{1}$ One way to characterize heavy tails is by the fact that for a sample of $n$ i.i.d. draws

$$
\lim _{s \rightarrow \infty} \frac{P\left\{\max \left(X_{1}, \ldots, X_{n}\right)>s\right\}}{P\left(\sum_{i=1}^{n} X_{i}>s\right)}=1 .
$$

Thus the sum is almost entirely driven by the maximum of the observations. 


\subsection{The linkage measure}

Instead of using the correlation measure to capture the dependence between two variables, we will directly study the probability of an extreme loss of a variable, conditional on the loss of another variable. Our indicator is therefore a conditional probability measure. The concern of regulators and risk managers is a simultaneous loss at the banking division and the insurance division of a financial conglomerate. More specifically, suppose a regulator wants to know the probability that $B>t$, given that $A>t$ and the probability that $A<t$ given that $B<t$, where $A$ and $B$ are the stochastic loss returns of the two divisions, and $t$ is the common high loss level. Since we are interested in a crash of the banking division given the crash of the insurance division and vice versa, we will condition on either event. Let $\kappa$ be the number of divisions which crash. We propose to use the linkage measure as the measure of systemic risk

$$
E[\kappa \mid \kappa \geq 1]=\frac{P(A>t)+P(B>t)}{1-P(A \leq t, B \leq t)} .
$$

This measure gives the expected number of divisions which crash, given that one division crashes. Hartmann et. al. (2004) provide further motivation for this measure. Note that

$$
E[\kappa \mid \kappa \geq 1]-1=\frac{P(A>t, B>t)}{1-P(A \leq t, B \leq t)}
$$

is the conditional probability that both divisions fail, given that there is a failure of at least one of the divisions. We will use either interpretation, depending on the context.

Unless one is willing to make further assumptions, as in the options based distance to default literature, it is impossible to pin down the exact level at which a division fails, or at which supervisors consider the institution financially unsound. For this reason we do take limits and consider

$$
\lim _{t \longrightarrow \infty} E[\kappa \mid \kappa \geq 1]
$$

Extreme value theory then shows that even though the measure is evaluated in the limit, it nevertheless provides a useful benchmark for the dependency at high but finite levels of $t$. We also like to note that the measure can be easily adapted in case failure levels at the divisions are different, in which case the measure is evaluated along a non $45^{\circ}$ line, in the $A, B$ space. 


\section{An economic rationale for dependence}

To give a theoretical rationale for dependence between banks and insurers, we give a stylized representation of the insurance and banking risks, using an elementary factor model. The factors are assumed to follow a distribution with non-normal heavy tails. This provides us with a characterization of the level and degree of dependence. New financial products enhance the possibilities to transfer risk between and within financial institutions. We show this may lead to a convergence of the investment portfolios of banks and insurers. First, we will give examples of this convergence, followed by a short exposition on the approach taken by financial institutions to manage this risk. We conclude by capturing the characteristics in a theoretical model.

The investments of banks and insurers are to a certain degree similar. Both invest in syndicated loans, have proprietary investments in equity and both hold mortgage portfolios. This may cause similarities in the risk profile of banks and insurers. Moreover, the costs arising out of liabilities for banks and insurers are to some degree similar. Both, for example, sell products with a guaranteed interest rate. New financial instruments can transform insurance risk to financial investments (e.g. catastrophe bonds) or can transform default risk to insurance risk, via credit default swaps. Via securitization of bank loan portfolios, the scope of investments for insurers is widened.

There are also differences. The interest rate exposure for banks and insurers differs. Banks hold relatively short term liabilities compared to their assets, while insurers hold relatively short term assets compared to their liabilities. On the liability side of banks balance sheets, the deposit contract exposes the banks to the risk of immediate callability, while insurers do not have such a risk. Thus there are similarities and differences in the risk profiles of banks and insurers, but we cannot say a priori which feature dominates. The empirical investigation addresses this latter issue. If we find that cross-sector dependence is lower than dependence within the two sectors, this may provide an argument for cross-sector mergers. However mergers are not always necessary to exploit those advantages, since risks can be traded between firms. For some risks this might be difficult, since the seller of protection has less information about the risk it receives than the buyer possesses. As a starting point for the discussion on the benefits of crosssector mergers, we model cross-sector dependence.

Banks and insurers develop risk management models to identify the risk of their institution. A study by the Basel Committee on Banking Supervision 
(2001) gives an overview of the different risk types that can be found in a financial conglomerate. Once the aggregate risk by risk type is known, one can investigate the dependence between risk types. The concept of economic capital makes it possible to measure the degree of risk taking. Although the distribution function of the risk types differ, the economic capital framework sets a common standard in terms of a confidence interval in the cumulative loss distribution within a specific time horizon.

Findings by Oliver, Wyman \& Company (2001) suggest that the largest benefits of diversification are obtained within a specific risk type, are smaller at the business line level and are even smaller across business lines. The current regulatory framework, which is designed for specific (sectoral) business lines, does not reflect possible diversification opportunities between banks and insurers. The predominant risk is often the primary focus of the current regulation. Internal risk models, which are increasingly used in modern regulation, are better fit to allow for diversification possibilities.

We focus on a semi-reduced form approach at the risk level of an institution. This implies that we do not form a complete structural model explaining the full strategy of agents, since we are primarily interested in the resulting risk. Of importance is the interdependency between institutions. We first model dependence theoretically and subsequently turn to an empirical evaluation. The model is related to the Arbitrage Pricing Theorem of Ross (1976). Suppose the risk of all firms in the financial sector can be decomposed into three elements. Firms face a common component of risk (macro risk), an insurance or bank sector specific risk (sector risk) and firm specific risk. We therefore assume total firm risk to be the sum of the financial market risk, $F$; risk within a sector, $A$ and $B$; and firm specific risks, $Y_{i}$ and $Z_{j}$. A high realization of a variable should be interpreted as a large loss, so we can focus on positive random variables for the study of our downside risk. This way we can turn the study of minima into the study of maxima, which permits a more expedient presentation.

The fat tail assumption for the loss distribution boils down to the assumption that the tails exhibit power like behavior, as in the case of the Pareto distribution. For ease of presentation we assume that the entire loss distribution is Pareto distributed. But we emphasize that the results carry over to all distributions which exhibit regular varying tails, such as the Student$\mathrm{t}$ distribution. Assume that the downside risk of the individual stochastic 
portfolio items $\left(A, B, F, Y_{i}, Z_{j}\right)$ are (unit scale) Pareto distributed on $[1, \infty)$

$$
P(F>t)=P(A>t)=P(B>t)=P\left(Y_{i}>t\right)=P\left(Z_{j}>t\right)=t^{-\alpha},
$$

where $t$ is the threshold loss level in which we are interested. In the following we investigate the dependence between two financial firms or divisions, depending on the interpretation. We distinguish two cases, investigating dependence within a sector and across sectors. The analysis of the theoretical risk exposures helps us to interpret the dependence between the tail risk of the different firms. Understanding this downside risk is desirable from a policy perspective, since it points to the benefits and limits of cross-sector risk sharing.

\subsection{Same sector dependence}

Before we can proceed, we need to introduce some theoretical tools. The probability of a large loss for a combination of risk factors when these exhibit a power like distribution, is given by Feller's convolution theorem (1971, VIII.8). This theorem holds that if two independent random variables $A$ and $B$ satisfy (2), then for large $t$ the convolution has probability

$$
P(A+B>t)=2 t^{-\alpha} L(t)
$$

and where $L(t)$ is slowly varying (i.e. $\lim _{t \longrightarrow \infty} L(a t) / L(t)=1$, for any $a>0$ ). The theorem implies that for large failure levels $t$, the convolution of $A$ and $B$ can be approximated by the sum of the univariate distributions of $A$ and $B$. All that counts for the probability of the sum is the (univariate) probability mass which is located along the two axes from the points onward where the line $A+B=t$ cuts the axes. The probability that the convolution of $A$ and $B$ is larger than $t$, for large $t$, is therefore

$$
P(A+B>t)=2 t^{-\alpha}+o\left(t^{-\alpha}\right) .
$$

Consider the dependency between two financials within the same sector. We use a stylized model of the downside risk of banks and insurers to analyze the tail dependence between two companies. To this end define the equity returns of a company in the banking sector $G_{i}$ or the insurance sector $H_{j}$ as a portfolio of risk factors consisting of the following elements:

$$
G_{i}=F+B+Y_{i} \text { and } H_{j}=F+A+Z_{j},
$$


where $F$ is broad financial market risk and $A$ and $B$ are the sector risks, which are similar for all firms within a sector. Bank and insurance specific risk is defined by $Y_{i}$ and $Z_{j}$. Using Feller (1971, VIII.8), for sufficiently large $t$ the probability that firm $i$ has a return larger than $t, P\left(G_{i}>t\right)$, is the sum of the probabilities that the individual portfolio factors are larger than $t$. Since the portfolio consists of three items, the probability of a crash of an individual company therefore reads

$$
P\left(F+B+Y_{i}>t\right)=3 t^{-\alpha}+o\left(t^{-\alpha}\right) .
$$

Suppose one is interested in the probability that two banks crash, simultaneously. The joint probability of a crash between two banks is equal to

$$
P\left(G_{1}>t, G_{2}>t\right)=P\left(F+B+Y_{1}>t, F+B+Y_{2}>t\right)=2 t^{-\alpha}+o\left(t^{-\alpha}\right) .
$$

This result can again be obtained from Feller's convolution theorem by the following argument. Note that the two portfolio inequalities $F+B+Y_{1}>t$ and $F+B+Y_{2}>t$, when satisfied simultaneously, only have the points above $t$ along the $F+B$ axis in the portfolio in $\operatorname{common}^{2}$, but not any point along the $Y_{1}$ or the $Y_{2}$ axes. This implies that for large $t$

$$
P\left(F+B+Y_{1}>t, F+B+Y_{2}>t\right) \approx P(F+B>t)=2 t^{-\alpha}+o\left(t^{-\alpha}\right)
$$

where the last equality directly follows from Feller's theorem. The probability of a joint crash among two insurers is similar, $P\left(H_{1}>t, H_{2}>t\right) \approx 2 t^{-\alpha}$. The relative magnitudes of these probabilities become clear in the empirical section, where we calculate the risk for cross-sector dependence.

\subsection{Cross-sector dependence}

In this paragraph we investigate the probability of a simultaneous crash in two different sectors. Since the sector risk for the two companies is different, there are less common components (factors) in the portfolio of the two firms. The probability of a joint crash of an insurer and a bank is lower, by the assumption that the sector specific portfolio items are independent,

$$
P\left(G_{1}>t, H_{1}>t\right)=P\left(F+B+Y_{1}>t, F+A+Z_{1}>t\right) \approx t^{-\alpha}+o\left(t^{-\alpha}\right) .
$$

\footnotetext{
${ }^{2}$ Note that the sum of $F$ and $B$ can be treated as a single random variable.
} 
This probability can also be derived using Feller's convolution theorem. When the portfolio inequalities $F+B+Y_{1}>t$ and $F+A+Z_{1}>t$ hold simultaneously, there is only probability mass of order $t^{-\alpha}$ above $t$ along the $F$ axis in common, and no mass of this order along the $\left(B+Y_{1}\right)$ and $\left(A+Z_{1}\right)$ axes. This implies that for large $t$

$$
P\left(F+B+Y_{1}>t, F+A+Z_{1}>t\right) \approx P(F>t)=t^{-\alpha}+o\left(t^{-\alpha}\right) .
$$

In Table 1 the probabilities of cross-sector and same sector risk are summarized. It is interesting to note that the probability of a joint crash of two companies differs considerably depending on cross-sector or within sector combinations.

To evaluate cross-sector dependence and dependence within the same sector with the linkage measure, we need to substitute for the probabilities in the numerator and denominator of (1). The probabilities for the numerator are given in (4). By using our previous assumptions on the risk components of individual banks and insurers, we can calculate the denominator. The probability that both banks face a return smaller than or equal to $t$, i.e. $P\left(G_{1} \leq t, G_{2} \leq t\right)$ can be calculated by using the complement $1-P\left(G_{1} \leq\right.$ $\left.t, G_{2} \leq t\right)$. If we examine the complement, for sufficiently large $t$, we have the probability that at least one bank has a return larger than $t$. A company has a return larger than $t$ if $F, A, B, Y_{i}$ or $Z_{j}$ is larger than $t$. The complement $1-P\left(G_{1} \leq t, G_{2} \leq t\right)$ is therefore equal to the sum of the probabilities that an individual portfolio component is larger than $t$, minus the probability of a joint failure. The complement $1-P\left(G_{1} \leq t, G_{2} \leq t\right)$ is approximately equal to $4 t^{-\alpha}$, since 4 different portfolio items $\left(F, B, Y_{1}\right.$ and $\left.Y_{2}\right)$ each have the probability of order $t^{-\alpha}$ to be larger than $t$. In Table 1 the complement $1-P\left(G_{1} \leq t, G_{2} \leq t\right)$ for two firms from a similar sector and two firms from a different sectors are given.

The conditional expectation of a crash of two firms in the same sector is given in (8)

$$
\lim _{t \longrightarrow \infty} E[\kappa \mid \kappa \geq 1]=\lim _{t \longrightarrow \infty} \frac{P\left(G_{i}>t\right)+P\left(G_{j}>t\right)}{1-P\left(G_{i} \leq t, G_{j} \leq t\right)}=\frac{6}{4} .
$$

The conditional expectation is much higher in the case of same sector dependence than in the case of cross sector dependence. The conditional expectation of a crash of two firms in different sectors is only

$$
\lim _{t \rightarrow \infty} E[\kappa \mid \kappa \geq 1]=\lim _{t \rightarrow \infty} \frac{P\left(G_{i}>t\right)+P\left(H_{j}>t\right)}{1-P\left(G_{i} \leq t, H_{j} \leq t\right)}=\frac{6}{5} .
$$




\begin{tabular}{|c|c|c|}
\hline $\begin{array}{l}G_{i}=F+B+Y_{i} \\
G_{j}=F+B+Y_{j}\end{array}$ & $\begin{array}{c}P\left(G_{i}>t, G_{j}>t\right) \\
\quad \approx 2 t^{-\alpha}\end{array}$ & $\begin{array}{c}1-P\left(G_{i} \leq t, G_{j} \leq t\right) \\
\approx 4 t^{-\alpha}\end{array}$ \\
\hline $\begin{array}{l}G_{i}=F+B+Y_{i} \\
H_{j}=F+A+Z_{j}\end{array}$ & $\begin{array}{c}P\left(G_{i}>t, H_{j}>t\right) \\
\approx t^{-\alpha}\end{array}$ & $\begin{array}{c}1-P\left(G_{i} \leq t, H_{j} \leq t\right) \\
\approx 5 t^{-\alpha}\end{array}$ \\
\hline
\end{tabular}

Table 1: Cross sector dependence

The dependence within a sector is higher than across sectors, because the banks and insurers have different sectoral specific risks $A$ and $B$.

\subsection{Dependence and the normal distribution}

It is interesting to note that the dependence in the tail disappears if we assume that the factors, $A, B, F, Y_{i}$ and $Z_{j}$ are standard (independently) normally distributed. Note that normality immediately implies that $G_{i}, G_{j}, H_{i}$ and $H_{j}$ are all correlated. Even though there is positive correlation, if the returns of both $G_{i}$ and $H_{i}$ follow a bivariate normal distribution there is no dependence between firms for large values of $t$, or

$$
\begin{gathered}
\lim _{t \longrightarrow \infty} E[\kappa \mid \kappa \geq 1]=\lim _{t \longrightarrow \infty} \frac{P\left(G_{i}>t\right)+P(G j>t)}{1-P\left(G_{i} \leq t, G_{j} \leq t\right)} \\
=\lim _{t \longrightarrow \infty} \frac{P\left(G_{i}>t\right)+P\left(H_{j}>t\right)}{1-P\left(G_{i} \leq t, H_{j} \leq t\right)}=1 .
\end{gathered}
$$

The proof for this result is similar to the proof of proposition 2 in De Vries (2005) and follows directly from the general result by Sibuya (1960). Therefore, under the assumption of normality, there is asymptotic independence between all possible combinations of firms, being banks or insurers. This explains why Figure 1a differs so much from Figure 1b, especially in the North-East and South-West corner, since the remake in Figure 1b is based on the assumption of normality. The disappearance of the dependency in the tail area is not unique for the normal distribution. The same holds for the assumption of exponentially distributed portfolio items.

To study whether there is dependence in the limit, we will compare our dependence estimates with estimation results of a bivariate normal model. First we present the univariate and bivariate estimators. 


\section{Estimators}

\subsection{Univariate estimators}

Extreme value theory studies the limit distribution of the (joint) maxima or minima of (return) series, as the sample size increases without bound. To study the minimum, we change the sign of the returns. Suppose that $X_{i}$ is an independent and identically distributed random variable with cumulative distribution function $F(x)$. This variable exhibits heavy tails if $F(x)$ far into the tails has a first order term identical to the Pareto distribution (see Appendix). We want to determine the probability that the daily stock return of a bank or insurer is lower than a prespecified loss level $x_{v a r}$, where the subscript refers to Value at Risk. To estimate this probability, we use the inverse quantile estimator from De Haan et al. (1994)

$$
\widehat{p}=\frac{m}{n}\left(\frac{X_{m+1}}{x_{v a r}}\right)^{\widehat{\alpha_{(m)}}}, \widehat{\alpha}_{(m)}=\frac{1}{m} \sum_{j=0}^{m} \ln \left(\frac{X_{j}}{X_{m+1}}\right) .
$$

This probability estimate depends on the tail index $\alpha$ estimator (based on the $m$ highest order statistics), the number of excesses $m$, the $m+1$-th order statistic $X_{m+1}$, the sample size $n$ and the threshold level $x_{v a r}$. This threshold level is where the Pareto approximation to the tail probabilities is appropriate. In our case $x_{v a r}$ is determined at $25 \%$. Details for this choice and further explanation of the estimation procedures are given in the Appendix. For the confidence interval of the quantile estimator we use the property that in the limit the estimator is normally distributed.

\subsection{Multivariate estimation}

In this paragraph we explain the estimator of the linkage measure (5). To develop an estimator for the linkage measure, note that

$$
E[\kappa \mid \kappa \geq 1]=\frac{P\left(X_{1}>t\right)+P\left(X_{2}>t\right)}{1-P\left(X_{1} \leq t, X_{2} \leq t\right)}=1+\frac{P\left(\min \left[X_{1}, X_{2}\right]>t\right)}{P\left(\max \left[X_{1}, X_{2}\right]>t\right)},
$$

where $P\left(\min \left[X_{1}, X_{2}\right]>t\right)$ is the probability that the minimum of $X_{1}$ and $X_{2}$ is above the threshold $t$, and $P\left(\max \left[X_{1}, X_{2}\right]>t\right)$ is the probability that the maximum of both random variables exceeds $t$. Both probabilities can be easily estimated using (10). In the Appendix we show that this can be done in 


$\begin{array}{lrlr} & \begin{array}{c}\text { Probability } \\ (X i<-0.25)^{*} 260\end{array} & \begin{array}{c}\text { Probability } \\ (\mathrm{Xi}<-0.25)^{*} 260\end{array} \\ \text { Banks } & 0.0037 & \text { ROYAL \& SUN } & 0.0482 \\ \text { HSBC } & 0.0064 & \text { AEGON } & 0.0584 \\ \text { RBS } & 0.0142 & \text { AVIVA } & 0.0161 \\ \text { UBS } & 0.0068 & \text { PRUDENTIAL } & 0.0237 \\ \text { BARCLAYS } & 0.0081 & \text { LEGAL \& GENERAL } & 0.0020 \\ \text { BSCH } & 0.0186 & \text { ALLEANZA } & 0.0070 \\ \text { BBVA } & 0.0089 & \text { SKANDIA } & 0.0501 \\ \text { DEUTSCHE BANK } & 0.0072 & \text { GENERALI } & 0.0121 \\ \text { ABN AMRO } & 0.0150 & \text { AXA } & 0.0153 \\ \text { UNICREDITO } & 0.0168 & \text { ZFS } & 0.1073 \\ \text { STD CHARTERED } & & & \\ & 0.0106 & & 0.0340 \\ \text { Average } & 0.0085 & & 0.0199 \\ \text { Median } & & & \end{array}$

Table 2: Univariate loss probabilities

one swap and that this estimator captures the limiting dependence between two heavy tailed random variables. Since we evaluate the limit behavior of (11), we take $t$ close to the boundary of the sample and use $t=0.075$. We obtain a confidence band by the Jackknife resampling procedure and show that our results do not change much if we omit a large number of observations (see Appendix).

\subsection{Data}

Our sample consists of the ten largest European banks and the ten largest European insurers. These firms were selected on the basis of balance sheet criteria such as the amount of customer deposits and life and non-life premium income. Insurers can provide both life insurance and non-life insurance (e.g. property and casualty insurance). We use daily data from January 1992 until December 2003. A precise description of the dataset is given in the Appendix.

\section{Empirical results}

In this section we present the estimates of the downside risk of individual firms and the dependence between firms. First we present the univariate risk for banks and insurers, next we present the estimates of the dependency between firms. 


\subsection{Univariate results}

Suppose one is interested in the probability of a loss of market value of $25 \%$ or more in a single day. Since these probabilities are very small, we scaled these up by a factor of 260, so that the probabilities can be interpreted as the probability that in a year there is a day with a loss of $25 \%$. The estimated probabilities are given in Table 2. From the averages of the different sectors it is clear that insurers are more risky than banks. The average in the banking sector is 0.0106 , in the insurance sector the average probability is 0.034 . In other words, about once per thirty years there is a day on which an insurer loses $25 \%$ of its equity value. For banks this is only once per century. Within the different groups there are, however, large deviations from the sector means. The results for the banking sector range from 0.0037 to 0.0186. The results for the insurance sector are between 0.0020 and 0.1073 . We formally test our null-hypothesis that both groups have the same loss probability by using the Wilcoxon/Mann-Whitney signed ranks test. The probability that the equality hypothesis is valid is 0.064 . This implies that at the $90 \%$ significance level this equality is rejected. But clearly the differences are not large.

Using (14) from the Appendix, one can calculate a confidence band around the loss probabilities. Results are given in Table 3. In this table we use a threshold loss of $15 \% .^{3}$ Given the limited amount of data, even at this loss level several upper bounds of the confidence bands are equal to 1 . The difference between the point estimator and the upper bound of the interval is larger than the difference between the point estimator and the lower bound. This is also a result of the relatively small sample size $(n)$.

The estimates are derived by assuming that the tails of the return distributions are heavy tailed. Since we study events that have a high impact, but which materialize at a very low frequency, our estimated probabilities may at first sight appear very small. To put these probabilities in perspective, recall the Figures (1a) and (1b), which showed a huge discrepancy between the normal distribution and the empirical distribution. Suppose one calculated the loss probabilities for HSBC and ZFS (respectively the first and last company) from Table 3 under the assumption of normality. This gives $1.5 * 10^{-15}$ and $8.6 * 10^{-11}$ for respectively HSBC and ZFS. These figures are much lower than 0.00012 and 0.00148 . The entire Table 3 is recalculated

\footnotetext{
${ }^{3}$ Here we do not scale up the probabilites with 260 , so as to guarantee that the probabilities are between 0 and 1 .
} 


$\begin{array}{lcccc}\text { Firms } & \begin{array}{c}\text { Lower } \\ \text { Bound }\end{array} & \begin{array}{c}\text { Probability } \\ \mathbf{X} \mathbf{i}<-\mathbf{- 0 . 1 5}\end{array} & \begin{array}{c}\text { Upper } \\ \text { Bound }\end{array} & \text { Hill } \\ \text { HSBC } & 0.00005 & 0.00012 & 1.00000 & 4.14 \\ \text { RBS } & 0.00010 & 0.00020 & 1.00000 & 4.06 \\ \text { UBS } & 0.00015 & 0.00028 & 0.00478 & 3.23 \\ \text { BARCLAYS } & 0.00009 & 0.00019 & 1.00000 & 3.89 \\ \text { BSCH } & 0.00012 & 0.00024 & 0.01360 & 3.98 \\ \text { BBVA } & 0.00020 & 0.00037 & 0.00304 & 3.23 \\ \text { DEUTSCHE BANK } & 0.00012 & 0.00023 & 0.01908 & 3.75 \\ \text { ABN AMRO } & 0.00011 & 0.00023 & 0.04766 & 4.09 \\ \text { UNICREDITO } & 0.00018 & 0.00033 & 0.00346 & 3.43 \\ \text { STD CHARTERED } & 0.00020 & 0.00038 & 0.00297 & 3.49 \\ \text { ROYAL \& SUN } & 0.00055 & 0.00092 & 0.00276 & 3.14 \\ \text { AEGON } & 0.00059 & 0.00097 & 0.00281 & 2.86 \\ \text { AVIVA } & 0.00021 & 0.00038 & 0.00297 & 3.57 \\ \text { PRUDENTIAL } & 0.00027 & 0.00049 & 0.00263 & 3.28 \\ \text { LEGAL \& GENERAL } & 0.00004 & 0.00009 & 1.00000 & 4.85 \\ \text { ALLEANZA } & 0.00010 & 0.00019 & 1.00000 & 3.87 \\ \text { SKANDIA } & 0.00078 & 0.00125 & 0.00309 & 3.66 \\ \text { GENERALI } & 0.00012 & 0.00024 & 0.01274 & 3.21 \\ \text { AXA } & 0.00022 & 0.00042 & 0.00281 & 3.82 \\ \text { ZFS } & 0.00095 & 0.00148 & 0.00334 & 2.50\end{array}$

Table 3: Loss probabilities and confidence bands

\begin{tabular}{lcccc} 
& \multicolumn{2}{c}{ Mean } & \multicolumn{2}{c}{ Median } \\
& Bank & Insurer & Bank & Insurer \\
Bank & 1.1038 & 1.0744 & 1.095 & 1.069 \\
Insurer & 1.0744 & 1.1170 & 1.069 & 1.107 \\
\multicolumn{4}{c}{$E[\kappa \mid \kappa \geq 1]$}
\end{tabular}

Table 4: Summary estimation results

under the assumption of normality and is given in the Appendix in Table A.2.

\subsection{Multivariate results}

Is cross-sector dependence between banks and insurers lower than dependence between two firms within the same sector? Since we have 10 banks and 10 insurers in our dataset, we have results for 45 possible combinations of banks, 45 possible combinations of insurers and 100 possible combinations between banks and insurers. In Table 4 the estimation results for the 190 possible combinations are summarized. The results for all 190 combinations 
are given in the Tables A.3, A.4 and A.5, in the Appendix. The results of the multivariate estimation in Table 4 indicate that cross-sector dependence between banks and insurers is lower than dependence between two firms within the same sector. The average probability that two banks crash, given that one crashes is $10.3 \%$ (The linkage estimator returns 1.103, we subtract 1 and multiply with 100\%.). For insurers this probability is $11.7 \%$, which is not very different. The probability that an insurer crashes given that a bank crashes or that a bank crashes, given that an insurer crashes is $7.4 \%$. It is much lower than the $10.3 \%$ in the banking sector. This indicates that in general dependence is lower for cross-sector combinations. We formally test the null-hypothesis that cross-sector dependence and dependence within the banking sector is the same, by using the Wilcoxon/Mann-Whitney signed ranks test. The probability that the hypothesis is not rejected is $0.004 \%$ if we test whether dependence among banks is similar to dependence between banks and insurers. We conclude that the risk profile of the two groups is different. Using the same test procedure, we can also find that the probability that the risk for combinations of insurers is equal to combinations of insurers and banks is only $0.003 \%$. Thus the dependence between banks and insurers is also lower than the combinations of insurers.

On the firm level, there are sizable deviations from the average risk within the sector. Results for specific combinations of firms given in the Tables A.3, A.4 and A.5. The largest conditional probability of a crash of two firms is $37.5 \%$ and it involves two Spanish banks (Table A.3). Since $37.5 \%$ is much higher than the sector average of $10.3 \%$, it makes considerable difference which firms merge. A possible explanation for this high probability are the common exposure of the two Spanish banks to risks in Spain and Latin America.

To illustrate the scope of the result of $37.5 \%$ conditional crash probability, we calculate the conditional expected number of failures $\kappa$ in (1) under the assumption of independence. Under independence we get that

$E[\kappa \mid \kappa \geq 1]=\frac{P\left(F_{1}>t\right)+P\left(F_{2}>t\right)}{1-\left(P\left(F_{1} \leq t\right) * P\left(F_{2} \leq t\right)\right)}=1+\frac{1}{\frac{1}{0.0038}+\frac{1}{0.0035}-1}=1.0018$.

The number 1.0018 is considerably smaller than 1.375. It is therefore clear that there is quite a bit of dependence in the tails. This exercise delivers similar results for other combinations of firms.

To provide yet another perspective for the $37.5 \%$ result which does recognize the correlation, we have also calculated (1) assuming a multivariate 


\begin{tabular}{|c|c|c|}
\hline \multicolumn{3}{|c|}{ ROYAL \& SUN - AEGON } \\
\hline 1.194 & 1.225 & 1.257 \\
\hline \multicolumn{3}{|c|}{ AEGON - AVIVA } \\
\hline 1.097 & 1.111 & 1.125 \\
\hline \multicolumn{3}{|c|}{ RBS - STD CHARTERED } \\
\hline 1.056 & 1.091 & 1.100 \\
\hline \multicolumn{3}{|c|}{ RBS - LEGAL \& GENERAL } \\
\hline 1.000 & 1.000 & 1.000 \\
\hline \multicolumn{3}{|c|}{ BSCH - BBVA } \\
\hline 1.357 & 1.375 & 1.400 \\
\hline \multicolumn{3}{|c|}{ BSCH - LEGAL \& GENERAL } \\
\hline 1.063 & 1.063 & 1.071 \\
\hline
\end{tabular}

Table 5: Multivariate results and 90\% confidence bands

normal distribution function for the returns. Under the bivariate normality assumption, the dependence measure for the two Spanish banks is still only a paltry $7.9 \%$ (compared to the $37.5 \%$ under the fat tail assumption). The results are given in the Tables A.6, A.7 and A.8. From the Tables it is once again clear that the assumption of a normal distribution function for the returns underestimates the downside risk. The conditional expected number of failures $\kappa$ for the combination of HSBC and RBS is 1.083, while estimation based on normality gives 1.0044. Our measure therefore predicts that the conditional probability of a simultaneous crash is approximately 20 times higher for this combination than the normality based measure. For the pair Aviva and Aegon, the estimate of the linkage measure based on normality gives 1.0134. This is a factor 10 lower than 1.111 (if we subtract 1 ). Thus the normal based measure gives a completely different view on the tail dependence and essentially rules out the possibility of a joint crash. Estimates taking into account the fat tails are of an entirely different order and appear to be more in line with the facts, since we do observe joint failures repeatedly.

Table 5 reports the confidence bands for a number of the linkage measure estimates. The bounds of the confidence interval do not deviate considerably from the point estimator and are of the same order. The Jackknife procedure behind the confidence bands is given in the Appendix. In the central column 
one finds the point estimate from (15). In the left and right column one finds the $90 \%$ confidence interval. In the case of the combination of $\mathrm{BSCH}$ and Legal and General, the point estimator of (15) hits the lower bound. This is the result of the quite limited sample, of only 12 years of daily data, which is small if one studies bivariate dependence. Another interesting observation is that the conditional expectation of a combined crash for the combination of RBS and Legal and General is zero. This stems from the fact that there are no joint losses of $7.5 \%$ or larger for these companies. In this case the point estimator defaults to the lower bound and the resampling based construction of the confidence bands collapses.

\section{Conclusion}

The downside risk dependence between insurance and banking risks investigated in this paper is indicative for the risk of a financial conglomerate. A financial conglomerate may provide scope for risk diversification across the banking and insurance books. This may lower capital requirements and enhance the efficiency of the financial services sector. Alternatively, one could also imagine that the downside risk of a conglomerate is actually larger, due to diseconomies of scope.

To measure the scope for diversification, we first investigated the uses of the normal distribution. We showed that the normal distribution strongly underestimates the downside risk, since the return series of financial assets are fat tailed distributed. Given the focus on downside risk, we therefore allow for fat tails. Both for the univariate risks and the multivariate downside risks this gives a much better description of the downside risk than the normal approximation.

To understand the possible differences in cross-sector risk, we developed an analytical model in the theory section, which helps to interpret the tail dependence between banking and insurance risks. It provides an explanation for the dependence structure between banking and insurers. Given this structure, the model explains the differences between the dependence among firms within an industry and the dependence among firms from different sectors.

In the empirical section we first measure the riskiness of individual banks and insurers. This involves estimating the probability of a crash by using daily stock price data. The estimation results for individual firms provide information on the risk of individual institutions and allows for a cross-sector 
comparison of individual firm risk. The estimation results for individual firms point to the conclusion that banks are less risky than insurers. If we take into account the low probability of a crash, both banks and insurers may be considered as safe.

The main research question concerns whether the downside risk in the banking sector differs from the downside risk in the insurance sector. To this end we examine the dependence between combinations of firms, both within a sector and across sectors. We find that risk dependence between a bank and an insurer is significantly different from the dependence structure between two banks or between two insurers. The average probability that two banks crash, given that one crashes is $10.3 \%$. For insurers this probability is $11.7 \%$, which is not very different. The probability that an insurer crashes given that a bank crashes or that a bank crashes, given that an insurer crashes is 7.4\%. This is much lower than the $10.3 \%$ in the banking sector. It indicates that in general dependence is lower for cross-sector combinations.

The theoretical model gives an explanation for the lower dependence between banks and insurers. Apparently, there is a different downside risk for the sector specific risks for insurance and banking. This relatively low cross-sector dependence implies a smaller impact of financial conglomerates on systemic risk. It follows that capital requirements for financial conglomerates could be set below the sum of the capital requirements for the banking and insurance parts.

The Basle II capital framework does not take into account these diversification benefits. We recommend to explore the properties of risk diversification by financial conglomerates in future work on capital requirements. If lower capital requirements can be justified from a prudential point of view, this may enhance social welfare.

\section{References}

[1] De Bandt, O., and P. Hartmann, Systemic risk: a survey, in C.A.E. Goodhart and G. Illing, (ed.), Financial Crisis, Contagion and the lender of last resort: a book of readings, Oxford University Press, 249-298, London, 2002

[2] BCBS (Basel Committee on Banking Supervision), Capital requirements and bank behavior: The impact of the Basel Accord, Working Paper 
no.1, 1999

[3] BCBS, Risk Management Practices and Regulatory Capital, Basel Committee on Banking Supervision, Joint Forum, www.bis.org, Basel, 2001

[4] Berger, A. N., The Integration of the Financial Services Industry: Where are the Efficiencies?, FEDS Paper No. 2000-36, Federal Reserve Board, Washington D.C., 2000

[5] Bikker, J.A., and I.P.P. van Lelyveld, Economic versus Regulatory capital for financial conglomerates, Research Series Supervision 45, De Nederlandse Bank, 2002

[6] Boyer, B., M. Gibson, M. Loretan, Pitfalls in tests for changes in correlation, International Finance Discussion Paper, no. 5-97, Board of Governors of the Federal Reserve System, 1997

[7] Carow, K.A., Citicorp-Travelers Group merger: Challenging barriers between banking and insurance, Journal of Banking \& Finance, 25, 15531571, 2001

[8] Danielsson, J., L. de Haan, L. Peng and C.G. de Vries, Using a bootstrap method to choose the sample fraction in tail index estimation, Journal of Multivariate Analysis, 76, 226-248, 2001

[9] De Nicolo, G. and M.L. Kwast, Systemic risk and financial consolidation: Are they related?, Journal of Banking \& Finance 26, 861-880, 2002

[10] Estrella, A., Mixing and matching: Prospective financial sector mergers and market valuation, Journal of Banking \& Finance 25, 1469-1498, 2001

[11] Feller, W., An Introduction to Probability Theory and its Applications, Vol.II 2nd ed. Wiley, New York, 1971

[12] Forbes, K.J., and R. Rigobon, No contagion, only interdependence: measuring stock market comovements, Journal of Finance, 57, 2223-2262, 2002

[13] The Group of Thirty, Global institutions, national supervision and systemic risk, A study group report, Washington D.C., 1997 
[14] Gully, B., W. Perraudin and V. Saporta, Capital requirements for combined banking and insurance activities, Bank of England, London, 2001

[15] Haan, L. de, D. Jansen and K. Koedijk, Safety first portfolio selection, extreme value theory and long run asset risks, in J. Galambos (ed.), Extreme Value Theory and Applications, Kluwer, Dordrecht, 471-487, 1994

[16] Hartmann, P., S. Straetmans and C.G. de Vries, Asset market linkages in crisis periods, The Review of Economics and Statistics, 81, 313-326, 2004

[17] Hill, B., A simple general approach to inference about the tail of a distribution, The Annals of Statistics, 3, 1163-1173, 1975

[18] Jansen, D. and C.G. de Vries, On the frequency of large stock returns: Putting booms and busts into perspective, The Review of Economics and Statistics 73,18-24, 1991

[19] Laderman, E.S., The potential diversification and failure reduction benefits of bank expansion into nonbanking activities, Federal Reserve Bank of San Francisco, 1999

[20] Oliver, Wyman and Company, Study on the risk profile and capital adequacy of financial conglomerates, A study commissioned by: De Nederlandsche Bank, Pensioen- \& Verzekeringskamer, Stichting Toezicht Effectenverkeer, Nederlandse Vereniging van Banken, Verbond van Verzekeraars, 2001

[21] Ross, S.A., The arbitrage theory of capital asset pricing, Journal of Econommic Theory, 13, 341-360, 1976

[22] Sibuya, M., Bivariate extreme statistics, Annals of the Institute of Statistical Mathematics 11, 195-210, 1960.

[23] Swiss Re, Reinsurance - a systemic risk?, Sigma no.5, Zurich, 2003

[24] Vries, C.G. de, The simple economics of bank fragility, Journal of Banking \& Finance, 29, 803-825, 2005 


\section{A Appendix}

\section{A.1 Data selection}

Since it is common for financial companies in Europe to exploit a broad portfolio of activities in banking and insurance, it is difficult to construct a dataset of companies pursuing pure banking or insurance strategies. Moreover, some activities as for example the provision of mortgages, are common for all companies in both banking and insurance. In this section we will explain when we define a company being a bank or an insurer.

We distinguish three different categories: banks, insurers (combining property\&casualty and life insurance business) and financial conglomerates. The dataset contains companies from Europe (the EU and Switzerland). First, we have taken the largest firms by market capitalization in the following sectors from Datastream: banking, life insurance, insurance and other financial. We classified these companies on the basis of their annual accounts over 2002.

To be able to make a distinction between insurers and banks, we collected the following balance sheet items: 'customer deposits', 'technical provisions' and 'life-insurance risk born by the policy holder'. We suppose that those broad items are unique for specific sectors. The item 'customer deposits' is typical for banks, since they borrow money from the public. The item 'technical provisions' is typical for insurers, since it represents the size of provisions for future insurance claims. Another item typical for life insurance is 'life-insurance risk born by the policy holder', which represents provisions for future claims of life insurance policies. The three items were added up and we represented the customer deposits as a percentage of this sum of balance sheet items. When the percentage of deposits is larger than $90 \%$ we define a firm as a bank. When the sum of 'technical provisions' and 'life-insurance risk born by the policy holder' represented as a percentage of the sum of all three items is larger than $90 \%$, we define a firm as an insurer.

Furthermore we want to get an indication of the main activity of the insurers. We made a distinction between property and casualty insurers and life insurers and collected data on the net premium income of insurers. The net premiums are the gross premiums written minus the reinsurance cover. Since an insurer might choose to buy reinsurance cover for some lines of business, we argue that the net premium income gives the best information about whether an insurer is active in life insurance or in property and ca- 


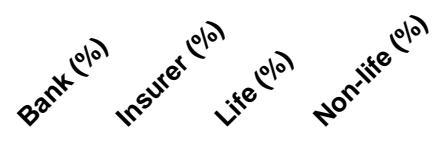

Bank
HSBC
RBS
UBS
BARCLAYS
BSCH
BBVA
DEUTSCHE BANK
ABN AMRO
UNICREDITO
STD CHARTERED
Insurer
GENERALI
AXA
AEGON
AVIVA
PRUDENTIAL
ZFS
LEGAL \& GENERAL
ALLEANZA
ROYAL \& SUN
SKANDIA

$\begin{array}{llll}0.98 & 0.02 & & \\ 0.96 & 0.04 & & \\ 1.00 & 0.00 & & \\ 0.95 & 0.05 & & \\ 1.00 & 0.00 & & \\ 1.00 & 0.00 & & \\ 0.98 & 0.02 & & \\ 0.97 & 0.03 & 0.78 & 0.22 \\ 1.00 & 0.00 & & \\ 1.00 & 0.00 & & \end{array}$

$\begin{array}{llll}0.00 & 1.00 & 0.65 & 0.35\end{array}$

$\begin{array}{llll}0.00 & 1.00 & 0.70 & 0.30\end{array}$

$\begin{array}{llll}0.03 & 0.97 & 0.96 & 0.04\end{array}$

$\begin{array}{llll}0.00 & 1.00 & 0.75 & 0.25\end{array}$

$\begin{array}{llll}0.06 & 0.94 & 0.98 & 0.02\end{array}$

$\begin{array}{llll}0.00 & 1.00 & 0.30 & 0.70\end{array}$

$\begin{array}{llll}0.00 & 1.00 & 0.94 & 0.06\end{array}$

$\begin{array}{llll}0.00 & 1.00 & 1.00 & 0.00\end{array}$

$\begin{array}{llll}0.00 & 1.00 & 0.82 & 0.18\end{array}$

$\begin{array}{llll}0.08 & 0.92 & 0.99 & 0.01\end{array}$

Table A.1: Selected data 


$\begin{array}{lcc} & P(X i<-0.15) & P(X i<-0.15)^{*} 260 \\ \text { HSBC } & 0.00000000000000 & 0.00000000000040 \\ \text { RBS } & 0.00000000000113 & 0.00000000029305 \\ \text { UBS } & 0.00000000000000 & 0.00000000000000 \\ \text { BARCLAYS } & 0.0000000000030 & 0.00000000007759 \\ \text { BSCH } & 0.00000000000041 & 0.00000000010585 \\ \text { BBVA } & 0.00000000000002 & 0.00000000000468 \\ \text { DEUTSCHE BANK } & 0.00000000000001 & 0.00000000000167 \\ \text { ABN AMRO } & 0.00000000000001 & 0.00000000000277 \\ \text { UNICREDITO } & 0.00000000004858 & 0.00000001263127 \\ \text { STD CHARTERED } & 0.00000000006859 & 0.00000001783248 \\ \text { ROYAL \& SUN } & 0.00000000503413 & 0.00000130887418 \\ \text { AEGON } & 0.00000000003063 & 0.00000000796488 \\ \text { AVIVA } & 0.00000000000205 & 0.00000000053240 \\ \text { PRUDENTIAL } & 0.00000000000330 & 0.00000000085795 \\ \text { LEGAL \& GENERAL } & 0.00000000000096 & 0.00000000024929 \\ \text { ALLEANZA } & 0.00000000000434 & 0.00000000112779 \\ \text { SKANDIA } & 0.00000116611496 & 0.00030318989027 \\ \text { GENERALI } & 0.00000000000000 & 0.00000000000000 \\ \text { AXA } & 0.00000000004009 & 0.00000001042234 \\ \text { ZFS } & 0.00000000008602 & 0.00000002236395\end{array}$

Table A.2: Univariate probability assuming normal cdf

sualty insurance. The life-insurance premium income was represented as a percentage of the total premium income.

We use data from 1992-2003, since in 1992 Basle I came into effect and because of data availability. Data is on a daily basis. Firms which are part of a larger conglomerate, like Winterthur which is a holding of Credit Suisse, are excluded. Some firms are omitted because the available data series is too short.

\section{A.2 Assuming normality}

To highlight the limits of the assumption of normality for the return distribution, we have calculated the risk of a loss of more than $15 \%$ on a given day for the different firms by using the normal distribution. The results can be found in Table A.2. These normal based probabilities are way below the corresponding extreme value distribution based fat tail hypothesis estimates from Table 3. 


\section{B Univariate estimation}

Extreme value theory studies the limit distribution of the maximum or minimum of a single return series. To study the minimum, we change the sign of the returns (focus on losses). Let $X_{i}$ be an independent and identically distributed random variable with cumulative distribution function $F(x)$. This variable exhibits heavy tails if $F(x)$ far into the tails has a first order term identical to the Pareto distribution, i.e.

$$
F(x)=1-x^{-\alpha} L(x) \text { as } x \rightarrow \infty,
$$

where $L(x)$ is a slowly varying function such that

$$
\operatorname{Lim}_{t \longrightarrow \infty} \frac{L(t x)}{L(t)}=1, x>0 .
$$

It can be shown that the two previous conditions are equivalent with

$$
\operatorname{Lim}_{t \longrightarrow \infty} \frac{1-F(t x)}{1-F(t)}=x^{-\alpha}, \alpha>0, t>0 .
$$

The coefficient $\alpha$ is known as the tail index and gives the number of bounded moments of the distribution. When a distribution has finite endpoints or exponentially decaying tails (like the normal and lognormal distributions), it fails the property of regular variation and all moments are bounded.

We estimate $\alpha$ with the Hill (1975) estimator:

$$
\widehat{\gamma}=1 / \widehat{\alpha}=\frac{1}{m} \sum_{j=0}^{m} \ln \left(\frac{X_{j}}{X_{m+1}}\right),
$$

where the parameter $m$ equals the number of highest order statistics. The number $m$ has to be selected such that the Pareto approximation of the tail is appropriate. We select the threshold by the bootstrap method proposed in Danielsson et al. (2001). In Figure 3 the Hill plots for four firms are given. In a Hill plot one varies the threshold $X_{m+1}$ or alternatively $m$, and plots $\widehat{\gamma}$ from (12) against $m$. In the Hill plots of Figure 3, where $\widehat{\gamma}$ is plotted against $m$, one sees considerable variation if one uses only the very top order statistics. Subsequently using more order statistics one notices some plateaus. Increasing $\mathrm{m}$ even further, the Hill plots all appear to be moving down. This is a result of the bias which kicks in when one uses too many central order 

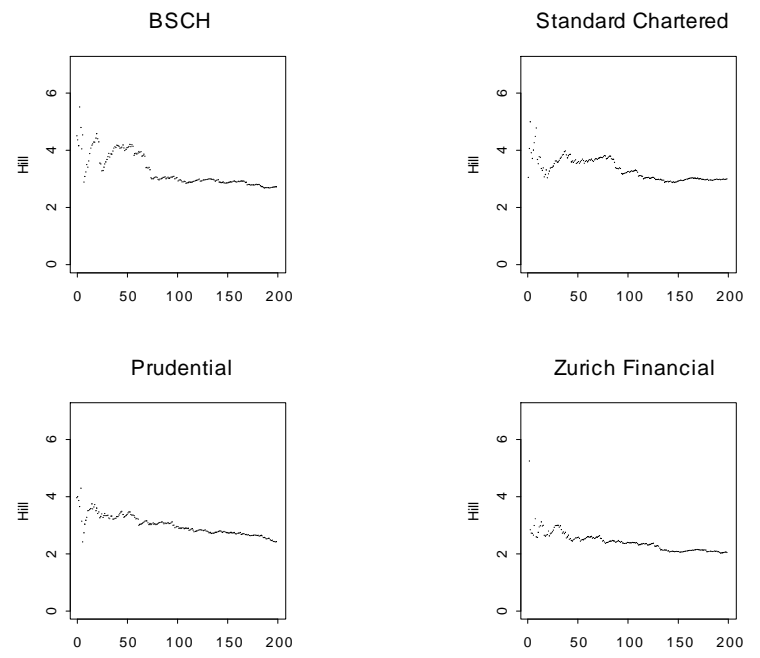

Figure 3: Hill plots for 4 firms

statistics. Using too few order statistics causes the variance to dominate. Somehow one has to sail between these two vices.

The next question is which threshold $m$ should be selected? We choose $m$ in such a way as to minimize the mean square error (mse), following Danielsson et al. (2001). This involves creating elaborate subsample bootstraps. Mean square error plots for four firms are given in Figure 4. The plots indicate that a minimum is reached around $m=50$. Since similar plots appear for all the series, we fixed $m$ at 50 for all our $\widehat{\gamma}$ estimates.

The objective of our investigation is to determine the probability that the daily stock return of a bank or insurer is lower than a prespecified probability level, $x_{v a r}$. To estimate this probability, we use the inverse quantile estimator from De Haan et al. (1994)

$$
\widehat{p}=\frac{m}{n}\left(\frac{X_{m+1}}{x_{v a r}}\right)^{\widehat{\gamma_{(m)}}} .
$$

This estimator depends on the inverse tail index $\gamma$, the number of higher order statistics $m$, the $m+1$-th order statistic $X_{m+1}$, the sample size $n$ and the level $x_{v a r}$. In our case $x_{v a r}$ is chosen at $25 \%$.

For the calculation of the confidence interval of this estimator we use the property of convergence of the estimator to normality in large samples. To 
calculate the $90 \%$ confidence interval for equation (13), we use the following from De Haan et al. (1994)

$$
\frac{m^{1 / 2}}{\log \left(\frac{x_{t}}{x_{p}}\right)}\left(\frac{\widehat{p}}{p}-1\right) \sim N\left(0, \alpha^{2}\right) .
$$

We rewrite this to obtain the lower bound and the upper bound of the $90 \%$ confidence interval for $p$

$$
\frac{\widehat{p}}{\frac{1.65 \hat{\alpha} f}{\sqrt{M}}+1}<p<\frac{\widehat{p}}{-\frac{1.65 \hat{\alpha} f}{\sqrt{M}}+1} \text { where } f=\log \left(\frac{x_{t}}{x_{p}}\right) \text {. }
$$

The $90 \%$ confidence intervals for $x_{v a r}>0.15$ are given in Table 3 , in the main text.
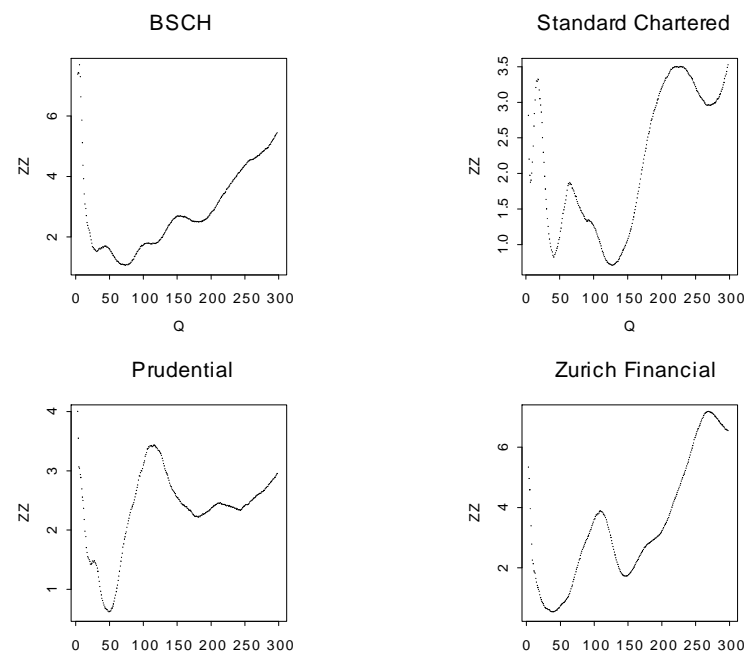

Figure 4: MSE 4 firms

\section{Multivariate estimation}

In this section we elaborate on the bivariate estimation technique employed in the paper. We first rewrite the linkage measure, turn it into an estimator 

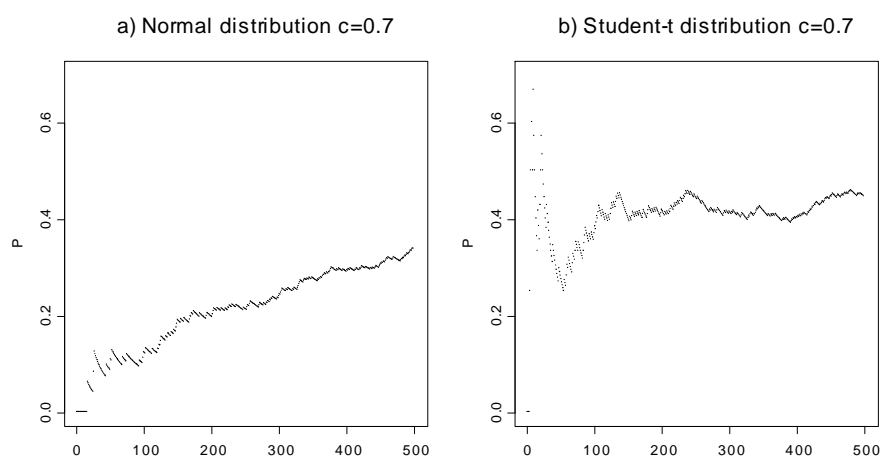

Figure 5: Conditional expectation, simulated data

and subsequently show how the estimator performs on simulated data en real data.

From elementary probability theory we know that $P\left(X_{1} \leq t, X_{2} \leq t\right)=$ $1-P\left(\max \left[X_{1}, X_{2}\right]>t\right)$ and $P\left(X_{1}>t\right)+P\left(X_{2}>t\right)=P\left(\max \left[X_{1}, X_{2}\right]>t\right)+$ $P\left(\min \left[X_{1}, X_{2}\right]>t\right)$. One can therefore rewrite the conditional expectation as follows

$$
E[\kappa \mid \kappa \geq 1]=\frac{P\left(X_{1}>t\right)+P\left(X_{2}>t\right)}{1-P\left(X_{1} \leq t, X_{2} \leq t\right)}=1+\frac{P\left(\min \left[X_{1}, X_{2}\right]>t\right)}{P\left(\max \left[X_{1}, X_{2}\right]>t\right)} .
$$

The estimation of the probability of multiple crashes can thus be reduced to the estimation of two univariate probabilities. This greatly facilitates the empirical analysis, since one can proceed on basis of the previously described univariate estimation methods by using the minimum and maximum return series. We use the notation $P_{\min }$ for $P\left(\min \left[X_{1}, X_{2}\right]>t\right)$ and the corresponding notation for the maximum. If the tail index $\alpha$ is identical for the minimum $\left(\alpha_{i}\right)$ and maximum $\left(\alpha_{a}\right)$ series, we obtain the following non-parametric estimator $^{4}$

$$
E[\kappa \mid \kappa \geq 1]=1+\frac{\widehat{P}_{\min }}{\widehat{P}_{\max }}
$$

${ }^{4}$ Using (13) and $E[\kappa \mid \kappa \geq 1]=1+\frac{\frac{M_{\min }}{n}\left(\frac{X_{M+1}}{x_{p}}\right)^{\widehat{\alpha_{i(m)}}}}{\frac{M_{\max }}{n}\left(\frac{X_{M+1}}{x_{p}}\right)^{\widehat{\alpha_{(}(m)}}}=1+\frac{M_{\min }}{M_{\max }}$, which shows that the estimator reduces to a simple counting procedure for the minima and maxima. 
In the following we show that this estimator captures the low dependence of a bivariate normal distribution, in comparison to the high dependence in the tails of a bivariate Student-t distribution. To this end we generate two times 5000 observations, based on the normal and Student-t distribution, with 3 degrees of freedom. We draw $q$ and $z$ from a normal distribution and define $a=q+0.7 z$. The correlation between $a$ and $z$ is therefore 0.7. This correlation pattern corresponds to the correlation which is present in Figure 1. However, from EVT it follows that the dependence in the tails between $a$ and $z$ is non-existent. This is also what the estimator (15) indicates, as can be seen in Figure 5a. The threshold $t$ is depicted on the x-axis, the linkage estimator is on the y-axis. High values for $t$ are on the left side. On sees that the dependence is low in the tails, i.e. for high values of $t$, but increases while going into the center of the distribution, when $t$ decreases.

Next, we generate $q$ and $z$ from a Student-t distribution, with 3 degrees of freedom and define $a=q+0.7 z$. The estimation results for the dependence between $a$ and $z$ can be found in Figure 5b. Contrary to the normal distribution, for large values of $t$ (on the left side of the Figure), there is dependence. This is exactly what one would expect on basis of the extreme value theory.

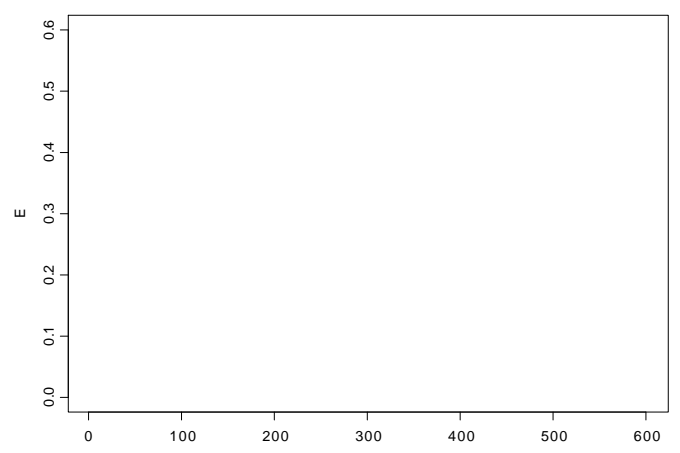

Figure 6: $E[\kappa \mid \kappa \geq 1]$ for ABN AMRO Bank and AXA

In Figure 6 we show the estimation results for real empirical data. The results of estimator (15) for the combination of ABN AMRO Bank and AXA looks very similar to the results of the Student-t simulation in Figure 5. 
$E[\kappa \mid \kappa \geq 1]$ is depicted at the y-axis. The threshold $t$ is on the $\mathrm{x}$-axis. Large $t$ are on the left, where $t$ is taken from the sorted, joint set of returns of AXA and ABN AMRO Bank. The value on the x-axis is the rank of $t$ in this joint sample. On the left side of the graph the variance is high, because there are few extremely large returns. The other side of the graph is relatively stable and there is not much variation. The interesting feature of this graph is however that for large $\mathrm{t}, E[\kappa \mid \kappa \geq 1]$ is still bounded away from zero. This is exactly what is the case in the generated graph for the bivariate Student-t distribution. The conditional probability of a simultaneous crash in normal distributed data is close to zero for large t.

The calculation of the confidence interval is based on resampling. We use a Jackknife procedure. To this end we divided the data in 20 blocks of 156 observations. We then apply estimator (15) twenty times, each time leaving one block of 156 observations out of the time series. To obtain the confidence band, the highest and lowest estimation results were removed, the next highest and lowest provide the $90 \%$ confidence interval. The point estimator is estimated using the full sample. 


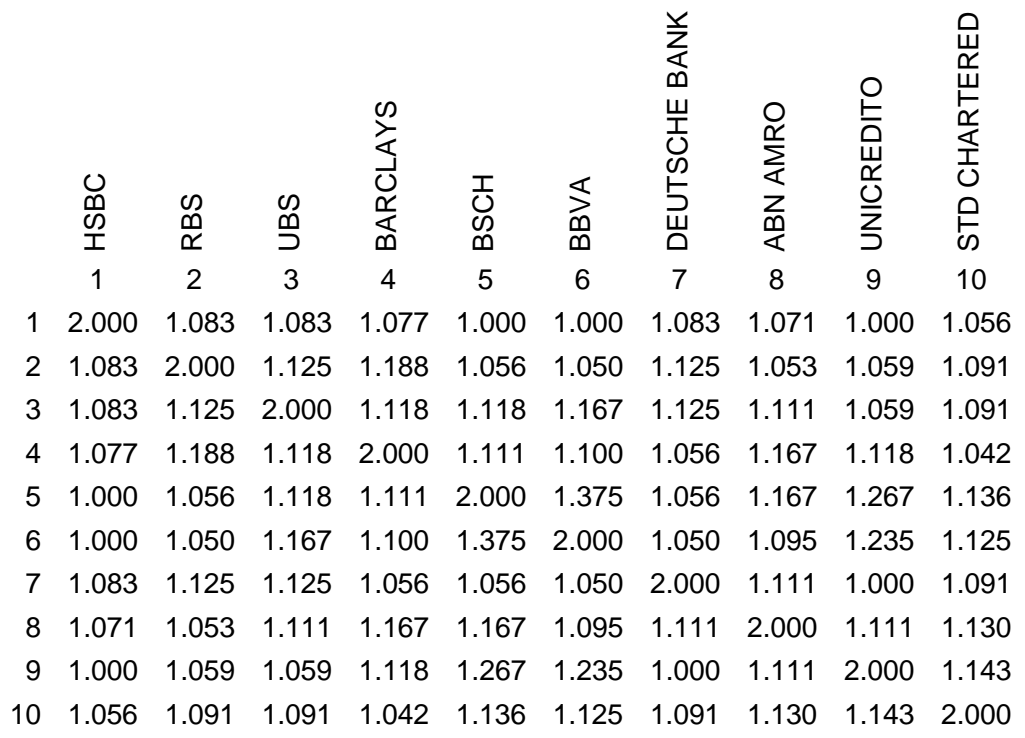

Table A.3: Banks vs Banks, $\mathrm{t}=0.075$, Real data

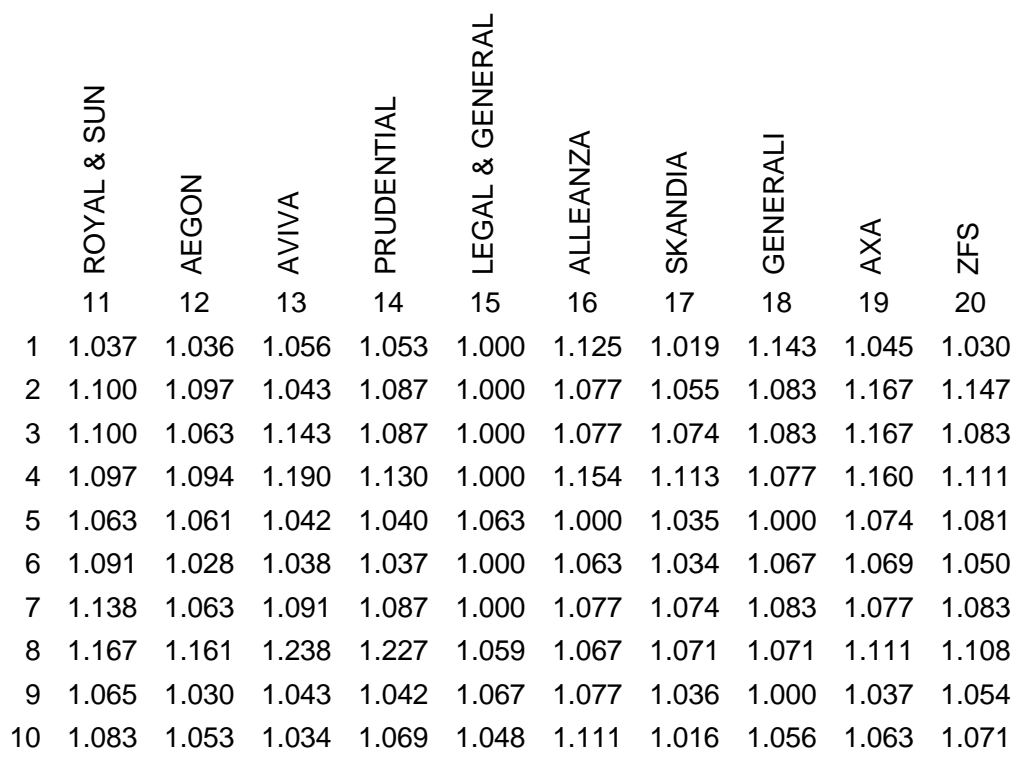

Table A.4: Banks vs Insurers, $\mathrm{t}=0.075$, Real data 


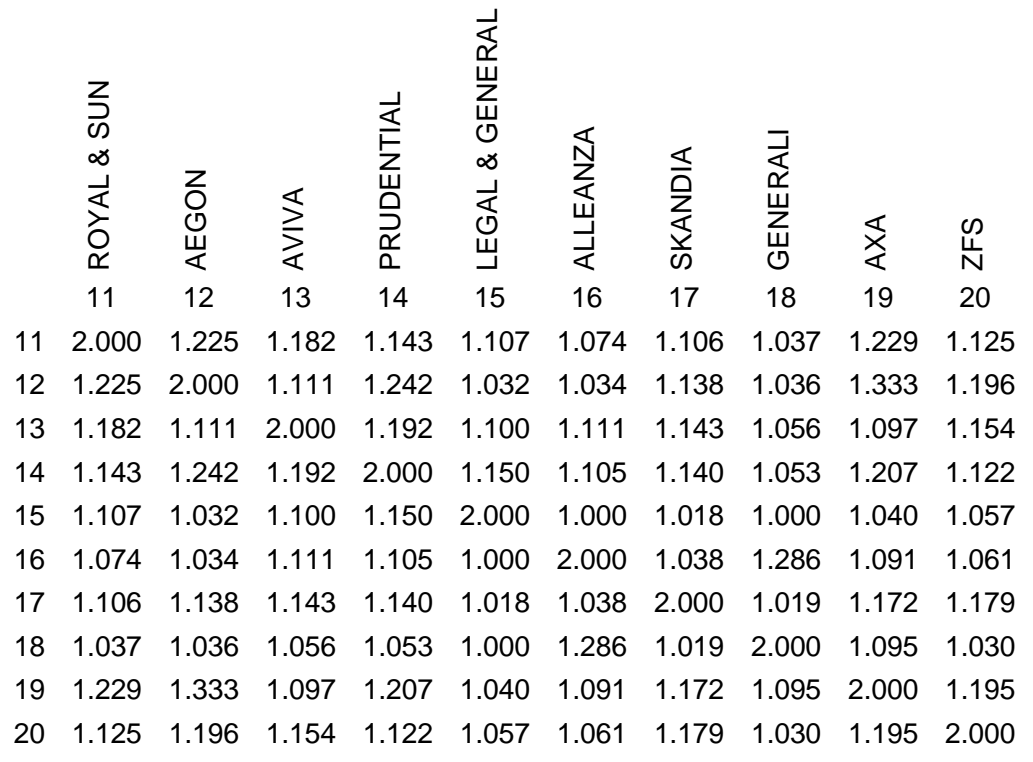

Table A.5: Insurers vs Insurers, $\mathrm{t}=0.075$, Real data

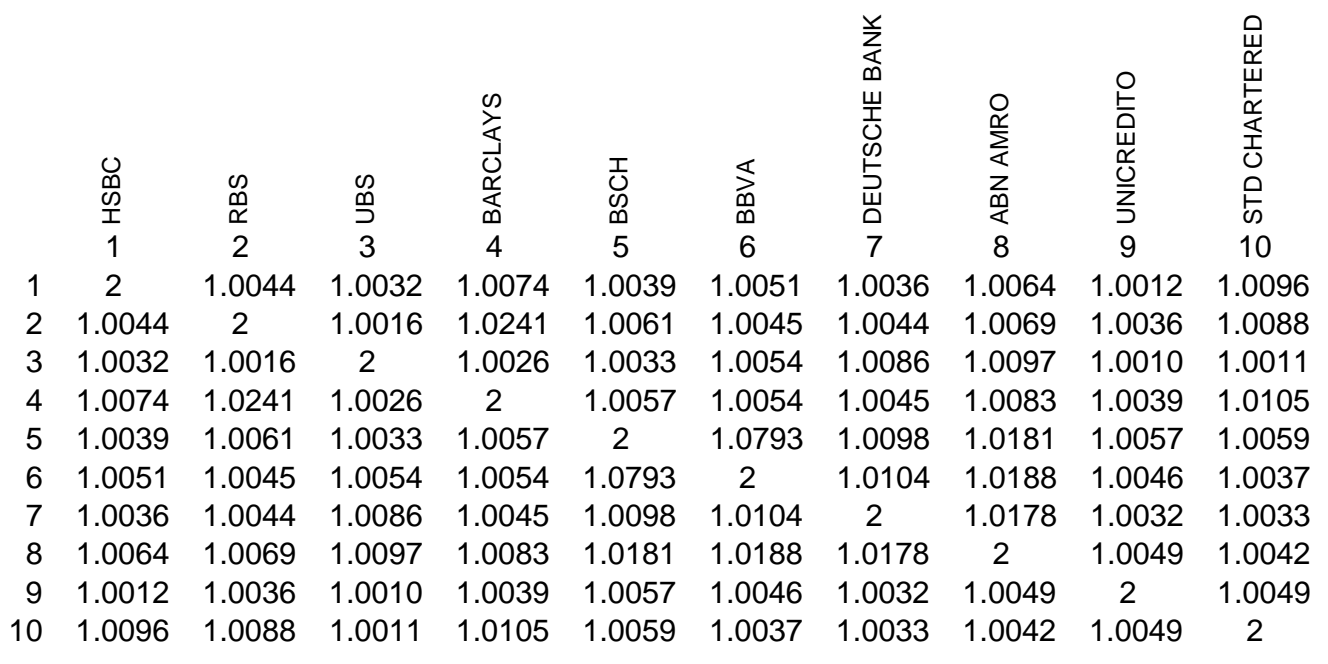

Table A.6: Bank vs Banks, $\mathrm{t}=0.075$, Bivariate normal 


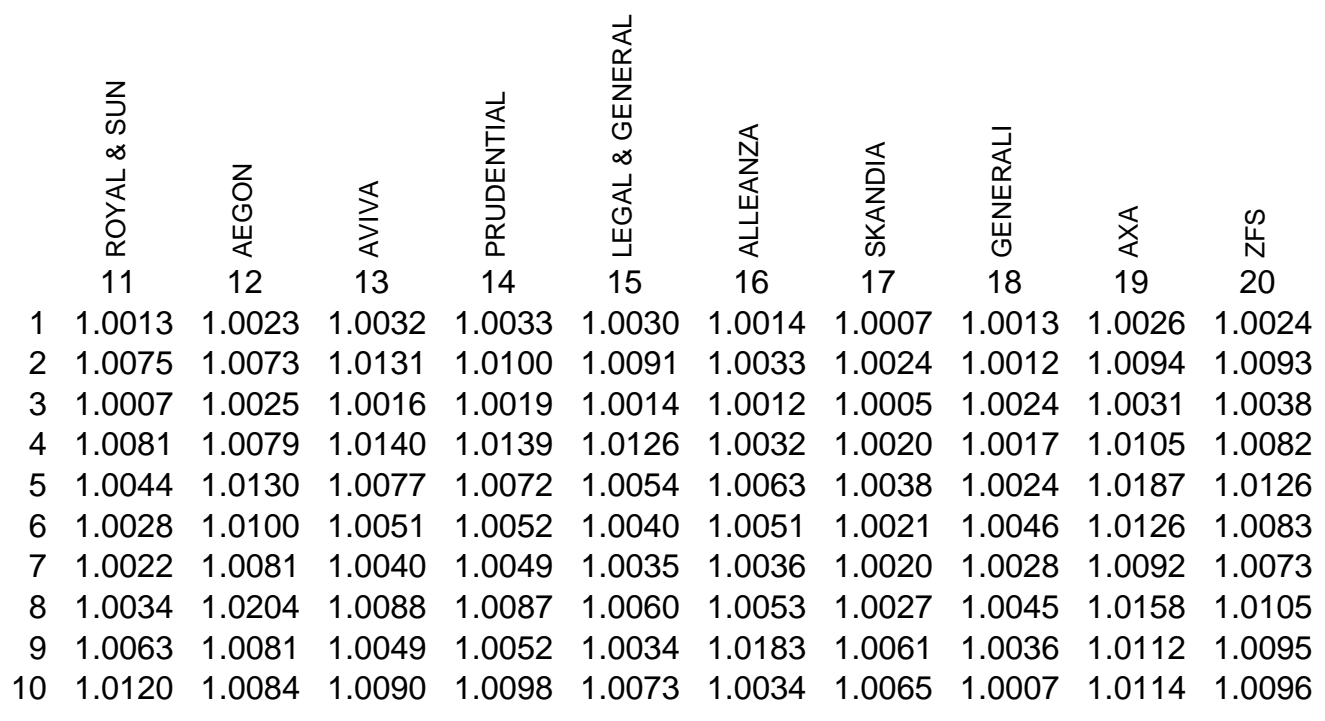

Table A.7: Bank vs Insurers, $\mathrm{t}=0.075$, Bivariate normal

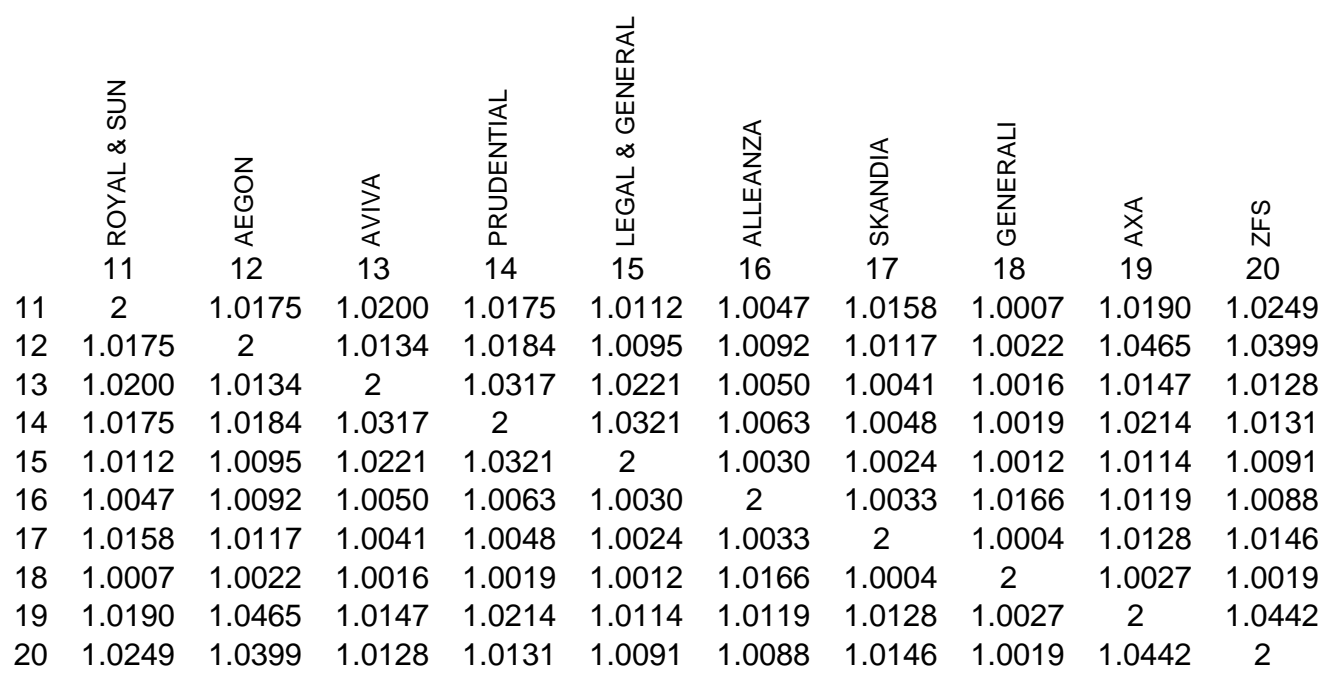

Table A.8: Insurers vs Insurers, $t=0.075$, Bivariate normal 